\title{
LCAO Electronic Structure of Nucleic Acid Bases and Other Heterocycles and Transfer Integrals in B-DNA, including Structural Variability
}

\author{
Marilena Mantela ${ }^{1}\left(\mathbb{D}\right.$, Constantinos Simserides ${ }^{1, *}$ (D) and Rosa Di Felice $2,3, *(\mathbb{D})$ \\ 1 Department of Physics, National and Kapodistrian University of Athens, Panepistimiopolis, Zografos, \\ GR-15784 Athens, Greece; mmantela@phys.uoa.gr \\ 2 Department of Physics and Astronomy and Department of Quantitative and Computational Biology, \\ University of Southern California, Los Angeles, CA 90089, USA \\ 3 CNR-NANO Modena, I-41125 Modena, Italy \\ * Correspondence: csimseri@phys.uoa.gr (C.S.); difelice@usc.edu (R.D.F.)
}

Citation: Mantela, M.; Simserides, C.; Di Felice, R. LCAO Electronic Structure of Nucleic Acid Bases and Other Heterocycles and Transfer Integrals in B-DNA, Including Structural Variability. Materials 2021, 14, 4930. https://doi.org/10.3390/ ma14174930

Academic Editor: Cédric Delattre

Received: 22 July 2021

Accepted: 23 August 2021

Published: 30 August 2021

Publisher's Note: MDPI stays neutral with regard to jurisdictional claims in published maps and institutional affiliations.

Copyright: (c) 2021 by the authors. Licensee MDPI, Basel, Switzerland. This article is an open access article distributed under the terms and conditions of the Creative Commons Attribution (CC BY) license (https:/ / creativecommons.org/licenses/by/ $4.0 /)$
Abstract: To describe the molecular electronic structure of nucleic acid bases and other heterocycles, we employ the Linear Combination of Atomic Orbitals (LCAO) method, considering the molecular wave function as a linear combination of all valence orbitals, i.e., $2 \mathrm{~s}, 2 \mathrm{p}_{x}, 2 \mathrm{p}_{y}, 2 \mathrm{p}_{z}$ orbitals for $\mathrm{C}, \mathrm{N}$, and $\mathrm{O}$ atoms and 1 s orbital for $\mathrm{H}$ atoms. Regarding the diagonal matrix elements (also known as on-site energies), we introduce a novel parameterization. For the non-diagonal matrix elements referring to neighboring atoms, we employ the Slater-Koster two-center interaction transfer integrals. We use Harrison-type expressions with factors slightly modified relative to the original. We compare our LCAO predictions for the ionization and excitation energies of heterocycles with those obtained from Ionization Potential Equation of Motion Coupled Cluster with Singles and Doubles (IP-EOMCCSD)/aug-cc-pVDZ level of theory and Completely Normalized Equation of Motion Coupled Cluster with Singles, Doubles, and non-iterative Triples (CR-EOMCCSD(T)) / aug-cc-pVDZ level of theory, respectively, (vertical values), as well as with available experimental data. Similarly, we calculate the transfer integrals between subsequent base pairs, to be used for a Tight-Binding (TB) wire model description of charge transfer and transport along ideal or deformed B-DNA. Taking into account all valence orbitals, we are in the position to treat deflection from the planar geometry, e.g., DNA structural variability, a task impossible for the plane Hückel approach (i.e., using only $2 \mathrm{p}_{z}$ orbitals). We show the effects of structural deformations utilizing a 20mer evolved by Molecular Dynamics.

Keywords: charge transfer; DNA; nucleic acids; Linear Combination of Atomic Orbitals (LCAO); Molecular Dynamics (MD); Tight Binding (TB); heterocycles

\section{Introduction}

The study of the electronic structure of organic heterocyclic molecules has been of interest for the scientific community for decades, especially since the establishment of investigation methods based on quantum mechanics. This includes the electronic structure and properties of nucleic acid oligomers and polymers, DNA and RNA. The sequence of bases, adenine $(A)$, thymine $(T)$ or uracil $(U)$, guanine $(G)$, cytosine $(C)$, is where genetic information is stored and transferred in all living organisms. The understanding of its electronic structure and charge transfer [1] properties is a crucial issue in biology, involved in functions such as damage and repair, carcinogenesis and mutagenesis [2-4], mutations and diseases [5-8] and is also important for novel applications in nanotechnology [9,10].

The last two decades have witnessed a surge of studies of DNA as the basis for molecular wires and molecular electronics devices/circuits, based on self-assembly and specific base hybridization [11-15]. The prospect of using DNA in materials science stems from exploiting its properties of molecular recognition, assembly, and processing information [11] as well as its ability to transfer or transport charge. Among other theoretical 
and experimental attempts, the electronic structure of single DNA molecules has been resolved by transverse scanning tunneling spectroscopy and assigned to groups of orbitals originating from the molecular entities, i.e., nucleobases, backbone, counterions [12]. Properties of long-range charge transport in DNA and DNA-mediated charge transfer and mechanisms have been studied a for a long time now [13]. Furthermore, currents in the range of 10-100 pA have been measured in G4-DNA over distances in the range of $10-100 \mathrm{~nm}$ [14]. Today, DNA plays an increasingly important role in molecular electronics due to its structural and molecular recognition properties [15].

In this work, we calculate the ionization and excitation energies of nucleic acid bases and similar molecules as well as assemblies of DNA bases using a semi-empirical Linear Combination of Atomic Orbitals (LCAO) method that includes all valence orbitals with a novel parameterization developed by us. Additionally, using this approach, we obtain electronic parameters for charge (electron or hole) transfer along DNA, which can be employed to model electron and hole conductivity. We investigate the electronic structure of the four DNA bases A, T, G, C and of the two Watson-Crick H-bonded pairs A-T and G-C. We focus on the HOMO (Highest Occupied Molecular Orbital) and LUMO (Lowest Unoccupied Molecular Orbital) wave functions and energies. With the new LCAO parameterization developed by us in this work, we calculate the transfer matrix elements between stacking base pairs, for all possible combinations between them, for both electrons and holes, aiming at parameterizing a Tight-Binding (TB) wire model. We calculate the transfer matrix elements for ideal geometries, namely for planar bases and base pairs separated and twisted approximately by $3.4 \AA$ and $36^{\circ}$, respectively, relative to the double helix growth axis. Our results are compared with published experimental and computational (from first principles and simpler TB models) data for the HOMO and LUMO energies. Finally, the deformed base pairs pruned from several snapshots of a $500 \mathrm{~ns}$ Molecular Dynamics (MD) trajectory of a 20mer [16] are used in order to address the effects of structural variability in the electronic structure and charge transfer properties of B-DNA within the LCAO approach.

The rest of this article is organized in the following way: In Section 2, we develop the novel LCAO parameterization that includes all valence orbitals for nucleic acid bases (Section 2.1) and base pairs (Section 2.2). This methodology is not limited to these specific molecular systems but can be applied to similar heterocycles. Next, we obtain the ТВ parameters that are relevant for a wire model description of charge transfer and transport along B-DNA (Section 2.3). We also describe non ideal bases and base pairs obtained by MD (Section 2.4). In Section 3, we present our results on ionization and excitation energies of various heterocyclic planar molecules, including isolated DNA bases (Section 3.1). The onsite energies of base pairs and transfer integrals between stacked base pairs are presented in Section 3.2. We study the effects of structural variability on the electronic structure and charge transfer properties of B-DNA in Section 3.3. Finally, Section 4, contains our overall conclusions.

\section{Theory}

\subsection{LCAO with All Valence Orbitals for Nucleic Acid Bases or Similar Molecules}

We consider the state $|\beta\rangle$ of a nucleic acid base, or a similar molecule, as a linear combination of all valence orbital states $\left|\phi_{i v}\right\rangle$, i.e., $2 \mathrm{~s}, 2 \mathrm{p}_{x}, 2 \mathrm{p}_{y}, 2 \mathrm{p}_{z}$ for $\mathrm{C}, \mathrm{N}$, and $\mathrm{O}$ atoms, and $1 \mathrm{~s}$ for $\mathrm{H}$ atoms:

$$
|\beta\rangle=\sum_{v=1}^{N} \sum_{i=1}^{I} c_{i v}\left|\phi_{i v}\right\rangle .
$$

The index $v$ runs among all $N$ atoms of the molecule and the index $i$ runs among all $I$ orbital states of each atom, respectively. $|\beta\rangle$ obeys the Schrödinger equation

$$
\hat{H}_{B}|\beta\rangle=E_{B}|\beta\rangle \text {. }
$$


$\hat{H}_{B}$ is the Hamiltonian of the base (or other molecule), with eigenvalues $E_{B, k}$ and eigenvectors $|\beta\rangle_{k}$. Taking the bracket, using $\left\langle\phi_{j \mu}\right|$, Equation (2) gives the linear system of equations

$$
\sum_{v=1}^{N} \sum_{i=1}^{I}\left[\left(H_{B, j \mu i v}-E_{B} S_{j \mu i v}\right) c_{i v}\right]=0, \quad \mu=1, \ldots, N, \quad j=1, \ldots, I .
$$

The Hamiltonian matrix elements $H_{B, j u i v}$ are given by

$$
H_{B, j \mu i v}=\left\langle\phi_{j \mu}\left|\hat{H}_{B}\right| \phi_{i v}\right\rangle
$$

and the overlap matrix elements are

$$
S_{j \mu i v}=\left\langle\phi_{j \mu} \mid \phi_{i v}\right\rangle \approx \delta_{j \mu i v} .
$$

We notice that we have approximated $S_{j \mu i v}$ by $\delta_{j \mu i v}$. The system of Equation (3) is solved by numerical diagonalisation, giving the eigenenergies $E_{B k}$ and eigenvectors

$$
\left|\beta_{k}\right\rangle=\left[\begin{array}{c}
c_{11 k} \\
c_{12 k} \\
\vdots \\
c_{i v k} \\
\vdots \\
c_{I N k}
\end{array}\right] .
$$

To this end we need the values of the Hamiltonian matrix elements, $H_{B, j \mu i v}$. Regarding the diagonal matrix elements $H_{B, i v i v}$-also known as on-site energies-we utilize a novel parameterization, namely: $E_{\mathrm{H}(1 \mathrm{~s})}=-13.64 \mathrm{eV}$ for $\mathrm{H} 1 \mathrm{~s}$ orbitals, $E_{\mathrm{C}(2 \mathrm{~s})}=-13.18 \mathrm{eV}$ for C 2s orbitals, $E_{\mathrm{C}(2 \mathrm{p})}=-6.70 \mathrm{eV}$ for C 2p orbitals, $E_{\mathrm{N}(2 \mathrm{~s})}=-14.51 \mathrm{eV}$ for $\mathrm{N} 2 \mathrm{~s}$ orbitals, $E_{\mathrm{N}(2 \mathrm{p})}=-9.55 \mathrm{eV}$ for $\mathrm{N} 2 \mathrm{p}$ orbitals, $E_{\mathrm{O}(2 \mathrm{~s})}=-15.03 \mathrm{eV}$ for $\mathrm{O} 2 \mathrm{~s}$ orbitals, $E_{\mathrm{O}(2 \mathrm{p})}=-11.52 \mathrm{eV}$ for $\mathrm{O} 2 \mathrm{p}$ orbitals. As for the nondiagonal matrix elements $H_{B, j \mu i v}(\mu \neq v)$ referring to neighboring atoms, we utilize the Slater-Koster two-center interaction transfer integrals [17]

$$
\begin{aligned}
V_{\mathrm{ss}} & =V_{\mathrm{ss} \sigma}, \\
V_{\mathrm{sx}} & =\xi_{1} V_{\mathrm{sp} \sigma} \\
V_{\mathrm{xx}} & =\xi_{1}^{2} V_{\mathrm{pp} \sigma}+\left(1-\xi_{1}^{2}\right) V_{\mathrm{pp} \pi} \\
V_{\mathrm{xy}} & =\xi_{1} \xi_{2}\left(V_{\mathrm{pp} \sigma}-V_{\mathrm{pp} \pi}\right)
\end{aligned}
$$

with $\xi_{1}, \xi_{2}$ being the directional cosines of $\vec{d}=\vec{j} i$ which points from atom $i$ to atom $j$. Concerning the values of $V_{\mathrm{ss} \sigma}, V_{\mathrm{sp} \sigma}, V_{\mathrm{pp} \sigma}, V_{\mathrm{pp} \pi}$, we use the relevant expressions proposed by Harrison [18,19], of the form:

$$
V_{\chi}=\chi \frac{\hbar^{2}}{m d^{2}}
$$

with $m$ being the electron mass and $d$ being the two-center distance. The $\chi$ values that we propose here are: $\chi_{\mathrm{ss} \sigma}=-1.32, \chi_{\mathrm{sp} \sigma}=-1.42, \chi_{\mathrm{pp} \pi}=-0.73$ (slightly modified relative to the original Harrison constant), $\chi_{\mathrm{pp} \sigma}=2.22$. For each $\mathrm{H}$ orbital, the interactions are multiplied by a factor $b=0.70$ that resulted from the optimization. We arrived at the above parameterization after careful optimization by fitting the LCAO numerical results with the experimental values for the excitation and the ionization energies of nucleic acid bases $\mathrm{A}$, G, T, C, and U. To do so, we used the Nelder-Mead algorithm as implemented in Matlab software. All other nondiagonal matrix elements, referring to non-neighboring atoms, are assumed equal to zero, $H_{B, j \mu i v}=0$. In Tables 1 and 2 we summarize our LCAO parameters. 
Table 1. Diagonal matrix elements also known as on-site energies, in our LCAO parameterization (eV).

\begin{tabular}{ccccccc}
\hline$E_{\mathrm{H}(1 \mathrm{~s})}$ & $E_{\mathrm{C}(2 \mathrm{~s})}$ & $E_{\mathrm{C}(2 \mathrm{p})}$ & $E_{\mathrm{N}(2 \mathrm{~s})}$ & $E_{\mathrm{N}(2 \mathrm{p})}$ & $E_{\mathrm{O}(2 \mathrm{~s})}$ & $E_{\mathrm{O}(2 \mathrm{p})}$ \\
\hline-13.64 & -13.18 & -6.70 & -14.51 & -9.55 & -15.03 & -11.52 \\
\hline
\end{tabular}

Table 2. $\chi$ values of Harrison-type expressions for nondiagonal matrix elements, utilizing SlaterKoster two-center interaction transfer integrals, and the correction factor for interactions involving $\mathrm{H}$ atoms, in our LCAO parameterization.

\begin{tabular}{ccccc}
\hline$\chi_{\mathrm{ss} \sigma}$ & $\chi_{\mathrm{sp} \sigma}$ & $\chi_{\mathrm{pp} \pi}$ & $\chi_{\mathrm{pp} \sigma}$ & $b$ \\
\hline-1.32 & -1.42 & -0.73 & 2.22 & 0.70 \\
\hline
\end{tabular}

From the numerical diagonalization of the Hamiltonian matrix, one obtains the energy eigenvalues corresponding to the electronic spectrum of molecular orbitals. The occupied and unoccupied orbitals - and thus the HOMO and LUMO — can be found by counting all valence electrons contributed by the atoms of the molecule and arranging them successively in couples of different spin in accordance with the Pauli principle. The same treatment developed for DNA bases is applicable to other purines, pyrimidines, and similar molecules.

\subsection{LCAO with All Valence Orbitals for B-DNA Base Pairs}

Likewise, we obtain the HOMO and LUMO states of a B-DNA base pair or monomer. Let us call $N_{1}, N_{2}$ the number of atoms making up the two bases of the base pair. We consider the base pair or monomer state $|\alpha\rangle$ as a linear combination of all valence orbital states $\left|\phi_{i v}\right\rangle$, i.e., $2 \mathrm{~s}, 2 \mathrm{p}_{x}, 2 \mathrm{p}_{y}, 2 \mathrm{p}_{z}$ for $\mathrm{C}, \mathrm{N}$ and $\mathrm{O}$ atoms and $1 \mathrm{~s}$ for $\mathrm{H}$ atoms:

$$
|\alpha\rangle=\sum_{v=1}^{N_{1}+N_{2}} \sum_{i=1}^{I} c_{i v}\left|\phi_{i v}\right\rangle .
$$

The indexes $v$ and $i$ run among the $N_{1}+N_{2}$ atoms of the base pair and the $I$ orbitals of each atom, respectively. $|\alpha\rangle$ obeys the Schrödinger Equation

$$
\hat{H}_{A}|\alpha\rangle=E_{A}|\alpha\rangle \text {. }
$$

$|\alpha\rangle$ and $E_{A}$ are the eigenvectors and eigenenergies of the monomer or base pair Hamiltonian $\hat{H}_{A}$. By taking the bracket, using $\left\langle\phi_{j \mu}\right|$, Equation (13) gives the linear system of equations

$$
\sum_{v=1}^{N_{1}+N_{2}} \sum_{i=1}^{I}\left[\left(H_{A, j \mu i v}-E_{A} S_{j \mu i v}\right) c_{i v}\right]=0, \quad \mu=1, \ldots, N_{1}+N_{2}, \quad j=1, \ldots, I .
$$

The system of Equation (14) is solved by numerical diagonalisation, as well, giving the eigenenergies $E_{A k}$ and eigenvectors

$$
\left|\alpha_{k}\right\rangle=\left[\begin{array}{c}
c_{11 k} \\
c_{12 k} \\
\vdots \\
c_{i v k} \\
\vdots \\
c_{I\left(N_{1}+N_{2}\right) k}
\end{array}\right] .
$$

In this case, the values of the Hamiltonian matrix elements, $H_{A, j \mu i v}$, are expressed slightly differently. The matrix elements $H_{A, j \mu i v}$ with (a) $1 \leq v \leq N_{1}$ and $1 \leq \mu \leq N_{1}$, and (b) $N_{1}+1 \leq v \leq N_{1}+N_{2}$ and $N_{1}+1 \leq \mu \leq N_{1}+N_{2}$, are expressed in the same way 
as previously described for molecules. For the remaining matrix elements, we employ the Slater-Koster two-center interaction transfer integrals of Equations (7), (8), (9), (10) but in this case, the values of $V_{s s \sigma}, V_{s p \sigma}, V_{p p \sigma}, V_{p p \pi}$ are of the form

$$
V_{\chi}=\chi \frac{\hbar^{2}}{m d_{0}^{2}} e^{-\frac{2}{d_{0}}\left(d-d_{0}\right)}
$$

where $d_{0}=1.35 \AA$ is a typical covalent bond distance within a base. This difference stems from the fact that Harrison's relations are valid for interatomic distances of the size of covalent bonds. However, the B-DNA bases (A and T, or G and C) are connected with noncovalent hydrogen bonds to form a base pair. The length of hydrogen bonds is longer than the typical length $d_{0}$ of the covalent bond connecting neighboring atoms within a base. Thus, when dealing with interatomic distances of the size of hydrogen bonds and longer, Harrison's expressions of Equation (11) are replaced with the appropriate exponentially decaying expressions of the form of Equation (16) [20-22].

From the aforementioned diagonalization of the Hamiltonian matrix, we obtain the energy eigenvalues $E_{A}$-including HOMO and LUMO—of the electronic spectrum, as well as the corresponding eigenvectors (coefficients) $c_{i v}$ of a base pair.

\subsection{Coherent Charge Transfer and Transport Parameters for a TB Wire Model}

\subsubsection{Eigenstates}

The HOMO or LUMO state of a DNA segment, made up of $\mathcal{N}$ monomers, can be expressed as

$$
|\mathrm{DNA}\rangle=\sum_{\alpha=1}^{\mathcal{N}} v_{\alpha}|\alpha\rangle
$$

$|\alpha\rangle$ is the HOMO or LUMO state of monomer (base pair) $\alpha$ and $v_{\alpha}$ are time-independent quantities. The Hamiltonian, in second quantization notation, in this TB wire model approach, can be written as

$$
\hat{H}_{\mathrm{DNA}}=\sum_{\alpha=1}^{\mathcal{N}} E_{\alpha}|\alpha\rangle\left\langle\alpha\left|+\sum_{\alpha=1}^{\mathcal{N}-1} t_{\alpha, \alpha+1}\right| \alpha\right\rangle\left\langle\alpha+1\left|+\sum_{\alpha=2}^{\mathcal{N}} t_{\alpha, \alpha-1}\right| \alpha\right\rangle\langle\alpha-1| .
$$

$E_{\alpha}$ is the HOMO or LUMO on-site energy of monomer $\alpha$, and $t_{\alpha, \gamma}$ is the transfer integral between monomers $\alpha$ and $\gamma$. By substituting Equations (17) and (18) into the timeindependent Schrödinger equation

$$
\hat{H}_{\mathrm{DNA}}|\mathrm{DNA}\rangle=E_{\mathrm{DNA}}|\mathrm{DNA}\rangle,
$$

we arrive to a system of $\mathcal{N}$ coupled equations

$$
E_{\alpha} v_{\alpha}+t_{\alpha, \alpha+1} v_{\alpha+1}+t_{\alpha, \alpha-1} v_{\alpha-1}=E_{\mathrm{DNA}} v_{\alpha} .
$$

Equation (20) is equivalent to the eigenvalue-eigenvector problem

$$
H_{\mathrm{DNA}} \vec{v}=E_{D N A} \vec{v}
$$

$H_{\text {DNA }}$ is the Hamiltonian matrix of order $\mathcal{N}$ composed of the TB parameters (on-site energies and transfer integrals) and $\vec{v}$ is the vector matrix composed of the coefficients $v_{j}$. The diagonalization of $H_{\mathrm{DNA}}$ leads to the determination of the HOMO or LUMO eigenenergy spectra (eigenspectra) $\left\{E_{k}\right\}, k=1,2, \ldots, \mathcal{N}$ and of the occupation probabilities for each eigenstate, $\left|v_{j k}\right|^{2}$, where $v_{j k}$ is the $j$-th component of the $k$-th eigenvector. 


\subsubsection{Coherent Charge Transfer}

To describe charge transfer between stacked base pairs of double-stranded DNA, we suppose that an extra inserted electron travels through LUMOs, while an extra inserted hole travels through HOMOs. The time-dependent HOMO or LUMO state of the whole B-DNA segment, $|\mathrm{DNA}(t)\rangle$, is considered as a linear combination of base-pair HOMO or LUMO states with time-dependent coefficients

$$
|\operatorname{DNA}(t)\rangle=\sum_{\alpha} A_{\alpha}(t)|\alpha\rangle,
$$

where $|\alpha\rangle$ is the HOMO or LUMO state of the $\alpha$-th monomer and the sum is extended over all monomers of the B-DNA segment. Substituting Equations (18) and (22) to the time-dependent Schrödinger equation

$$
i \hbar \frac{d|\operatorname{DNA}(t)\rangle}{d t}=\hat{H}_{\mathrm{DNA}}|\mathrm{DNA}(t)\rangle,
$$

we obtain the system of $\mathcal{N}$ coupled differential equations:

$$
i \hbar \frac{A_{\alpha}}{d t}=E_{\alpha} A_{\alpha}+t_{\alpha, \alpha-1} A_{\alpha-1}+t_{\alpha, \alpha+1} A_{\alpha+1} .
$$

Equation (24) is equivalent to a first-order matrix differential equation, which can be solved with the eigenvalue method.

\subsubsection{Coherent Charge Transport}

To handle coherent charge transport in a TB approach, we also need the TB parameters (on-site energies and transfer integrals) described above. This can be done, e.g., with a transfer matrix approach [23].

\subsubsection{TB Parameters for a Wire Model Description}

The TB parameters for a wire model description of charge transfer or transport can be obtained as follows. The transfer integral between monomers $|\lambda\rangle$ and $\left|\lambda^{\prime}\right\rangle$

$$
t_{\lambda, \lambda^{\prime}}=\left\langle\lambda\left|\hat{H}_{D N A}\right| \lambda^{\prime}\right\rangle
$$

can be analyzed as

$$
t_{\lambda, \lambda^{\prime}}=\sum_{v=1}^{N_{\lambda}} \sum_{i=1}^{I_{\lambda}} \sum_{\mu=1}^{N_{\lambda^{\prime}}} \sum_{j=1}^{I_{\lambda^{\prime}}} c_{i v(\lambda)}^{*} V_{i v j \mu} c_{j \mu}\left(\lambda^{\prime}\right),
$$

where

$$
V_{i v j \mu}=\left\langle\phi_{i v(\lambda)}\left|\hat{H}_{\mathrm{DNA}}\right| \phi_{j \mu\left(\lambda^{\prime}\right)}\right\rangle .
$$

The matrix elements $V_{i v j u}$ are given by the Slater-Koster two-center interaction transfer integrals of Equations (7)-(10) with the values of $V_{\mathrm{ss} \sigma}, V_{\mathrm{sp} \sigma}, V_{\mathrm{pp} \sigma}, V_{\mathrm{pp} \pi}$ being of the form of Equation (16). The tight-binding parameters $E_{\lambda}$ and $t_{\lambda, \lambda^{\prime}}$ computed in this work could be used to treat charge transfer (Section 2.3.2) and transport (Section 2.3.3) along a BDNA segment.

Finally, we obtain the maximum transfer percentage of the carrier from one base pair to another. This refers to the maximum probability to find the extra hole or electron at the site where it was not placed at initially. The maximum transfer percentage reads

$$
p=\frac{(2 t)^{2}}{(2 t)^{2}+\Delta^{2}}
$$

where $t$ is the transfer parameter between the two base pairs and $\Delta$ is the difference between the HOMO or LUMO energies of the two base pairs. 


\subsection{DNA Fragments Generated by $M D$}

In order to study the effects of structural variability on the electronic structure and charge transfer parameters in B-DNA, we used multiple instances of AA and GG dimers. These instances were pruned from representative structures of the $500 \mathrm{~ns}$ MD trajectory of the 20mer $5^{\prime}-$ CGAAAAGGGGAAAAGGGGAT $-3^{\prime}$ at constant temperature $T=300 \mathrm{~K}$ and constant pressure $P=1$ bar. Specifically, we considered the centroid structures of the two most populated clusters, accounting for 35\% (cl1) and 12\% (cl2) of the whole trajectory. More details are given elsewhere [16]. From the two most representative 20mers we extracted all the possible AA and GG dimers (two stacked H-bonded base pairs), excluding the dimers of the edges. These dimers are denoted as: A4A5_cl1, A4A5_cl2, A5A6_cl1, A5A6_cl2, G7G8_cl1, G7G8_cl2, G8G9_cl1, G8G9_cl2, G9G10_cl1, G9G10_cl2, A11A12_cl1, A11A12_cl2, A12A13_cl1, A12A13_cl2, A13A14_cl1, A13A14_cl2, G15G16_cl1, G15G16_cl2, G16G17_cl1, G16G17_cl2. We denote the corresponding monomers as: A4_cl1, A4_cl2, A5_cl1, A5_cl2, A6_cl1, A6_cl2, G7_cl1, G7_cl2, G8_cl1, G8_cl2, G9_cl1, G9_cl2, G10_cl1, G10_cl2, A11_cl1, A11_cl2, A12_cl1, A12_cl2, A13_cl1, A13_cl2, A14_cl1, A14_cl2, G15_cl1, G15_cl2, G16_cl1, G16_cl2, G17_cl1, G17_cl2.

Local complementary base-pair parameters are employed in order to define the base pair structure and its variability. The parameters describing the relative translations in all axes, involving two bases of a Watson-Crick pair, are shear $(S x)$, stretch $(S y)$, and stagger $(S z)$, while the corresponding rotations around $x, y$, and $z$ axes are buckle $(\kappa)$, propeller twist $(\pi)$, and opening $(\sigma)$ [24]. Figure 1 depicts the definitions of these translation and rotation parameters involving two bases of a Watson-Crick pair.
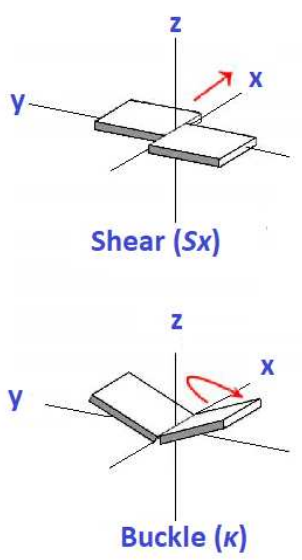
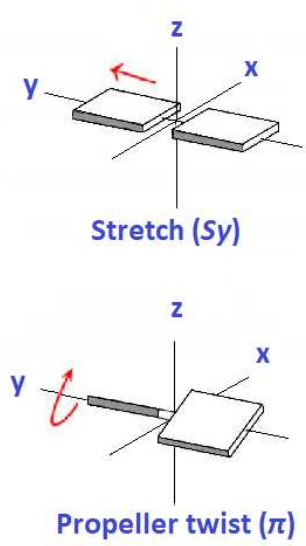
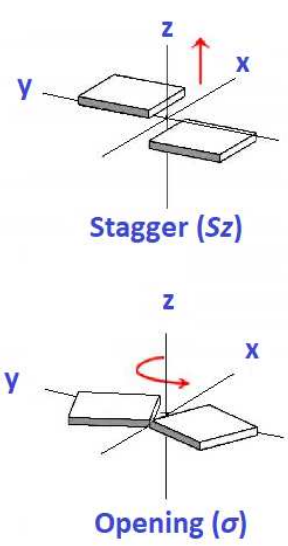

Figure 1. Definitions of translation parameters (top row) and rotation parameters (bottom row) involving two bases of a base pair.

Figure 2 sketches the translation and rotation parameters for each one of the studied monomers. The parameters were computed using the web interface 3DNA. Dashed lines denote the mean value of each parameter, that is: $0.03 \AA$ (shear), $-0.03 \AA$ (stretch), $0.04 \AA$ (stagger), $6.53^{\circ}$ (buckle), $-10.40^{\circ}$ (propeller twist), $1.06^{\circ}$ (opening) for A-T monomers and $-0.09 \AA$ (shear), $-0.04 \AA$ (stretch), $0.01 \AA$ (stagger), $0.55^{\circ}$ (buckle), $-1.13^{\circ}$ (propeller twist), $-0.66^{\circ}$ (opening) for G-C monomers. These values together with values found in the literature are listed in Table 3. 
Table 3. The second and third column contain mean values of translation and rotation parameters for monomers A-T and G-C, as studied in the present work. Other columns list values from bibliography.

\begin{tabular}{lcccccc}
\hline Parameter & A-T & G-C & {$[25]$} & [26] & [27] & [28] \\
\hline shear $(\AA)$ & 0.03 & -0.09 & 0.00 & -0.04 & & \\
\hline stretch $(\AA)$ & -0.03 & -0.04 & -0.15 & -0.17 & & \\
\hline stagger $(\AA)$ & 0.04 & 0.01 & 0.09 & 0.21 & & \\
\hline buckle $\left({ }^{\circ}\right)$ & 6.53 & 0.55 & 0.5 & 0.3 & $(-7.5,7.5)$ & \\
\hline propeller twist $\left(^{\circ}\right)$ & -10.40 & -1.13 & -11.4 & -13.7 & 11.5 & $-12.60 \pm 3.2$ \\
\hline opening $\left({ }^{\circ}\right)$ & 1.06 & -0.66 & 0.6 & 1.0 & $(-2,2)$ & \\
\hline
\end{tabular}
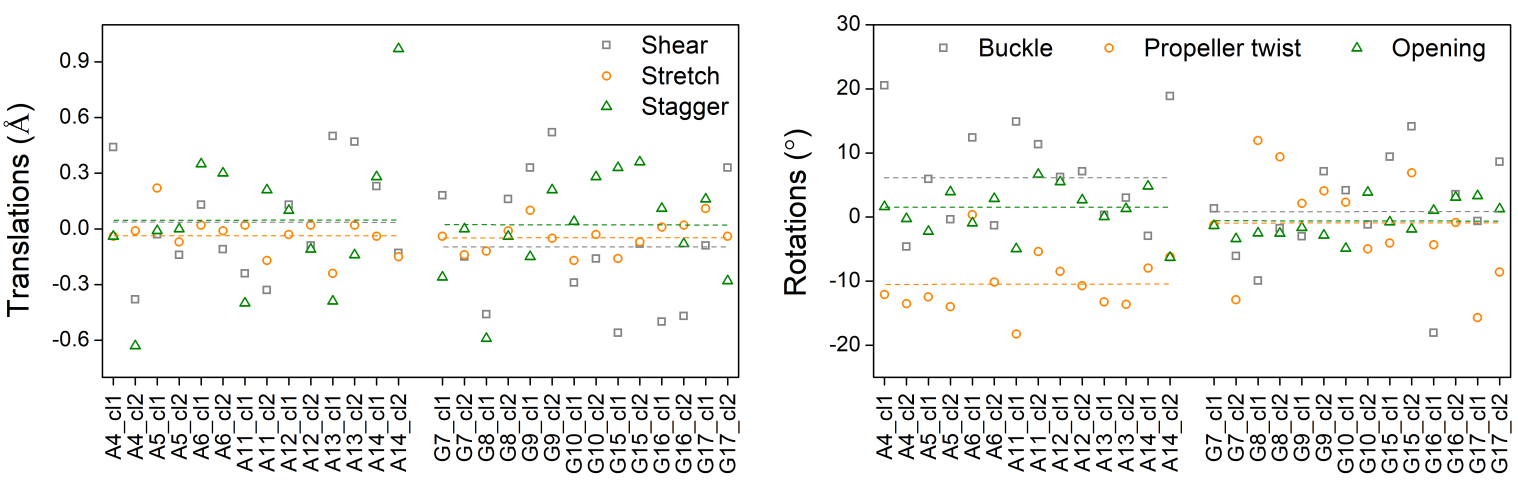

Figure 2. Translation (shear, stretch, stagger) and rotation (buckle, propeller twist, opening) parameters for all studied monomers. Dashed lines denote the mean value of each parameter.

\section{Results and Discussion}

\subsection{Heterocyclic Planar Molecules including Nucleic Acid Bases}

The theoretical scheme described in Section 2 was employed to calculate the HOMO and LUMO eigenenergies for a variety of heterocyclic planar organic molecules. We make the convenient simplifying assumption that the HOMO absolute value expresses the ionization energy, and the HOMO-LUMO gap expresses the excitation energy (in most cases the first $\pi-\pi^{*}$ transition). Below, the ionization energies are of $\pi$ molecular orbital character and the excitation energies are $\pi-\pi^{*}$ transitions, unless otherwise stated. We studied the following groups of molecules: adenine and isomers; guanine and isomers; purine and isomers; thymine, cytosine, uracil, and isomers; pyrimidine and isomers; and other planar heterocyclic molecules. Table 4 summarizes our LCAO results using all valence orbitals, along with relevant experimental values. $I_{\mathrm{CC}}$ and $E_{\mathrm{CC}}$ are calculations of the vertical ionization energies at the Ionization Potential Equation of Motion Coupled Cluster with Singles and Doubles (IP-EOMCCSD)/aug-cc-pVDZ level of theory and vertical excitation energies at the Completely Renormalised Equation of Motion Coupled Cluster with Singles, Doubles, and non-iterative Triples (CR-EOMCCSD(T))/aug-cc-pVDZ level of theory, respectively, ref. [29].

Table 4 also includes transition oscillator strengths $f$ that we calculated in a simplistic approximation, considering point contribution of the corresponding orbitals; i.e., the transition dipole moment $\vec{d}$ was approximated as 


$$
\begin{aligned}
\vec{d} & =(-e)\langle L|\vec{r}| H\rangle=(-e)\left(\sum_{v=1}^{N} \sum_{i=1}^{I} c_{i v L}^{*}\left\langle\phi_{i v}\right|\right) \vec{r}\left(\sum_{\mu=1}^{N} \sum_{j=1}^{I} c_{j \mu H}\left|\phi_{j \mu}\right\rangle\right) \\
& =(-e) \sum_{\nu=1}^{N} \sum_{i=1}^{I} \sum_{\mu=1}^{N} \sum_{j=1}^{I} c_{i v L}^{*} c_{j \mu H}\left\langle\phi_{i v}|\vec{r}| \phi_{j \mu}\right\rangle \simeq(-e) \sum_{v=1}^{N} \sum_{i=1}^{I} c_{i v L}^{*} \vec{r}_{i} c_{i v H},
\end{aligned}
$$

where $|L\rangle(|H\rangle)$ is the LUMO (HOMO) state. The oscillator strength is [30]

$$
f=\frac{2}{3} \frac{m}{e^{2} \hbar^{2}} E d^{2} .
$$

$E$ is the excitation energy. The results are illustrated in Figures 3-5.

Table 4. Ionization and excitation energies $(\mathrm{eV}) . I_{\mathrm{LCAO}}$ and $E_{\mathrm{LCAO}}$ are the ionization and excitation energies obtained by our LCAO scheme, including all valence orbitals. $f_{\mathrm{LCAO}}$ is the relevant oscillator strength. $I_{\mathrm{CC}}$ and $E_{\mathrm{CC}}$ are the energies

\begin{tabular}{|c|c|c|c|c|c|c|c|}
\hline Name Formula & $I_{\text {LCAO }}$ & $E_{\text {LCAO }}$ & $f_{\text {LCAO }}$ & $I_{\mathrm{CC}}$ & $E_{\mathrm{CC}}$ & $I_{\exp }$ & $E_{\exp }$ \\
\hline $\begin{array}{l}\text { Adenine } \\
\mathrm{C}_{5} \mathrm{H}_{5} \mathrm{~N}_{5} \\
\text { (Isomer 1) }\end{array}$ & 8.44 & 4.20 & 0.330 & 8.23 & 5.04 & $8.44[31]$ & $4.84[32,33]$ \\
\hline $\begin{array}{l}\text { 2-Aminopurine } \\
C_{5} H_{5} N_{5} \\
\text { (Isomer 2) }\end{array}$ & 8.56 & 3.84 & 0.239 & 7.95 & 4.27 & & $4.11[34]$ \\
\hline $\begin{array}{l}\text { 1H-pyrazolo[3,4-d] } \\
\text { pyrimidin-4-amine } \\
C_{5} H_{5} N_{5} \\
\text { (Isomer 3) }\end{array}$ & 8.78 & 4.25 & 0.328 & 8.51 & 4.92 & & \\
\hline $\begin{array}{c}\text { Pyrimido [5,4-e]-as- } \\
\text { triazine, } 1,2 \text {-dihydro- } \\
C_{5} H_{5} N_{5} \\
\text { (Isomer } 4 \text { ) }\end{array}$ & 8.04 & 3.21 & 0.282 & 7.18 & 3.16 & & \\
\hline $\begin{array}{l}\text { Guanine } \\
\mathrm{C}_{5} \mathrm{H}_{5} \mathrm{~N}_{5} \mathrm{O} \\
\text { (Isomer 1) } \\
\end{array}$ & 8.36 & 4.25 & 0.288 & 7.83 & $\begin{array}{l}4.77\left(\pi \rightarrow \sigma^{*}\right) \\
4.85\end{array}$ & $8.24[31]$ & $4.51[33]$ \\
\hline $\begin{array}{c}\text { 7-Amino-S-triazolo(1,5-a) } \\
\text { pyrimidin-5(4H)-one } \\
\mathrm{C}_{5} \mathrm{H}_{5} \mathrm{~N}_{5} \mathrm{O} \\
\text { (Isomer 2) }\end{array}$ & 8.42 & 4.37 & 0.285 & 8.60 & 4.91 & & \\
\hline $\begin{array}{c}\text { Pyrimido[5,4-e]-as-triazin- } \\
\text { 5[6h]-one, } 1,2 \text {-dihydro- } \\
\mathrm{C}_{5} \mathrm{H}_{5} \mathrm{~N}_{5} \mathrm{O} \\
\text { (Isomer 3) }\end{array}$ & 8.19 & 3.42 & 0.198 & 6.68 & 2.54 & & \\
\hline $\begin{array}{c}\text { 7H-imidazo[4,5-d]-v } \\
\text { triazin-4-one, 6-methyl- } \\
\mathrm{C}_{5} \mathrm{H}_{5} \mathrm{~N}_{5} \mathrm{O} \\
\text { (Isomer 4) }\end{array}$ & 8.93 & 3.64 & 0.302 & 8.92 & $\begin{array}{l}4.47\left(n \rightarrow \sigma^{*}\right) \\
4.55\end{array}$ & & \\
\hline $\begin{array}{l}\text { 9H-purine } \\
\mathrm{C}_{5} \mathrm{H}_{4} \mathrm{~N}_{4} \\
\text { (Isomer 1) }\end{array}$ & 9.20 & 4.40 & 0.313 & 9.34 & $\begin{array}{l}4.49\left(n \rightarrow \pi^{*}\right) \\
4.92\end{array}$ & $9.52[31]$ & $\begin{array}{l}4.28 \text { [35] }\left(n \rightarrow \pi^{*}\right) \\
4.68 \text { [35] }\end{array}$ \\
\hline $\begin{array}{c}\text { 7H-purine } \\
C_{5} H_{4} N_{4} \\
\text { (Isomer } 1 \text { taut.) }\end{array}$ & 9.08 & 4.26 & 0.295 & $\begin{array}{l}9.34(n) \\
9.40\end{array}$ & $\begin{array}{l}4.36\left(n \rightarrow \pi^{*}\right) \\
4.79\end{array}$ & & \\
\hline $\begin{array}{c}\text { 1H-1,2,3-triazolo } \\
\text { [4,5-b]pyridine } \\
\mathrm{C}_{5} \mathrm{H}_{4} \mathrm{~N}_{4} \\
\text { (Isomer 2) }\end{array}$ & 9.42 & 4.12 & 0.340 & 9.41 & $\begin{array}{l}4.49 \\
4.54\end{array}$ & & \\
\hline
\end{tabular}
calculated at the IP-EOMCCSD/aug-cc-pVDZ and CR-EOMCCSD(T)/aug-cc-pVDZ level of theory [29]. $I_{\exp }$ and $E_{\exp }$ are the experimental data. In parentheses, the character of the transition. 
Table 4. Cont.

\begin{tabular}{|c|c|c|c|c|c|c|c|}
\hline $\begin{array}{c}\text { Name } \\
\text { Formula }\end{array}$ & $I_{\mathrm{LCAO}}$ & $E_{\mathrm{LCAO}}$ & $f_{\text {LCAO }}$ & $I_{\mathrm{CC}}$ & $E_{\mathrm{CC}}$ & $I_{\text {exp }}$ & $E_{\text {exp }}$ \\
\hline $\begin{array}{c}{[1,2,4] \text { Triazolo }} \\
{[1,5 \text {-a]pyrazine }} \\
C_{5} H_{4} N_{4} \\
\text { (Isomer } 3 \text { ) }\end{array}$ & 8.95 & 4.20 & 0.230 & 9.27 & 4.63 & & \\
\hline $\begin{array}{c}{[1,2,3] \text { Triazolo }} \\
{[1,5 \text {-a]pyrazine }} \\
C_{5} H_{4} N_{4} \\
\text { (Isomer } 4 \text { ) }\end{array}$ & 8.64 & 3.96 & 0.172 & 8.95 & 4.31 & & \\
\hline $\begin{array}{l}\text { Thymine } \\
\mathrm{C}_{5} \mathrm{H}_{6} \mathrm{~N}_{2} \mathrm{O}_{2}\end{array}$ & 9.09 & 4.77 & 0.316 & 9.03 & $\begin{array}{l}5.07\left(n \rightarrow \pi^{*}\right) \\
5.17\end{array}$ & 9.14 [31] & 4.69 [33] \\
\hline $\begin{array}{l}\text { Cytosine } \\
\mathrm{C}_{4} \mathrm{H}_{5} \mathrm{~N}_{3} \mathrm{O}\end{array}$ & 8.68 & 4.54 & 0.306 & 8.67 & 4.64 & 8.94 [31] & 4.64 [33] \\
\hline $\begin{array}{c}\text { Uracil } \\
\mathrm{C}_{4} \mathrm{H}_{4} \mathrm{~N}_{2} \mathrm{O}_{2} \\
\text { (Isomer 1) }\end{array}$ & 8.89 & 4.70 & 0.286 & 9.44 & $\begin{array}{l}5.03\left(n \rightarrow \pi^{*}\right) \\
5.27\end{array}$ & $9.50[31]$ & $4.79[33,35]$ \\
\hline $\begin{array}{c}\text { Pyrazine, 1,4-dioxide } \\
\mathrm{C}_{4} \mathrm{H}_{4} \mathrm{~N}_{2} \mathrm{O}_{2} \\
\text { (Isomer 2) }\end{array}$ & 8.77 & 4.28 & 0.403 & 8.11 & 3.30 & 8.33 [36] & 4.05 [37] \\
\hline $\begin{array}{c}\text { 4(1H)-pyrimidinone, } \\
\text { 6-hydroxy- } \\
\mathrm{C}_{4} \mathrm{H}_{4} \mathrm{~N}_{2} \mathrm{O}_{2} \\
\text { (Isomer 3) }\end{array}$ & 9.01 & 4.95 & 0.103 & 9.66 & 5.29 & & \\
\hline $\begin{array}{c}\text { Maleic hydrazide } \\
\left.\mathrm{C}_{4} \mathrm{H}_{4} \mathrm{~N}_{2}\right)_{2} \\
(\text { Isomer } 4)\end{array}$ & 8.77 & 3.34 & 0.113 & 8.77 & 4.11 & & \\
\hline $\begin{array}{l}\text { Pyrazine } \\
\mathrm{C}_{4} \mathrm{H}_{4} \mathrm{~N}_{2} \\
\text { (Isomer 1) }\end{array}$ & 9.53 & 4.39 & 0.258 & $\begin{array}{l}9.49(n) \\
10.09\end{array}$ & $\begin{array}{l}4.07\left(n \rightarrow \pi^{*}\right) \\
4.88\end{array}$ & $\begin{array}{l}9.63[38] \\
10.18[38]\end{array}$ & $\begin{array}{l}4.20[39] \\
4.79[40,41]\end{array}$ \\
\hline $\begin{array}{l}\text { Pyrimidine } \\
\mathrm{C}_{4} \mathrm{H}_{4} \mathrm{~N}_{2} \\
\text { (Isomer 2) }\end{array}$ & 9.98 & 5.28 & 0.249 & $\begin{array}{l}9.56(n) \\
10.44\end{array}$ & $\begin{array}{l}4.41\left(n \rightarrow \pi^{*}\right) \\
4.84\left(n \rightarrow \pi^{*}\right) \\
5.25\end{array}$ & $\begin{array}{l}9.73[38] \\
10.41[38]\end{array}$ & $\begin{array}{l}4.35[39] \\
4.62[40] \\
5.13[33,35,40,41]\end{array}$ \\
\hline $\begin{array}{l}\text { Pyridazine } \\
\mathrm{C}_{4} \mathrm{H}_{4} \mathrm{~N}_{2} \\
\text { (Isomer 3) }\end{array}$ & $\begin{array}{l}9.41(n) \\
10.39\end{array}$ & $\begin{array}{l}4.28 \\
5.26\end{array}$ & $\begin{array}{l}0.000\left(n \rightarrow \pi^{*}\right) \\
0.253\end{array}$ & $\begin{array}{l}9.07(n) \\
10.59\end{array}$ & $\begin{array}{l}3.76\left(n \rightarrow \pi^{*}\right) \\
4.47\left(n \rightarrow \pi^{*}\right) \\
5.12\end{array}$ & $\begin{array}{l}9.31[38] \\
10.61[38]\end{array}$ & $\begin{array}{l}3.70[39] \\
5.00[41]\end{array}$ \\
\hline $\begin{array}{c}\text { 1H-imidazole } \\
\mathrm{C}_{3} \mathrm{H}_{4} \mathrm{~N}_{2} \\
\text { (Isomer 1) }\end{array}$ & 8.80 & $\begin{array}{l}4.97 \\
5.77\end{array}$ & $\begin{array}{l}0.000\left(\pi \rightarrow \sigma^{*}\right) \\
0.171\end{array}$ & 8.90 & $\begin{array}{l}5.50\left(\pi \rightarrow \sigma^{*}\right) \\
6.29\end{array}$ & 8.96 [42] & 5.99 [43] \\
\hline $\begin{array}{c}\text { 1H-pyrazole } \\
\mathrm{C}_{3} \mathrm{H}_{4} \mathrm{~N}_{2} \\
\text { (Isomer 2) }\end{array}$ & $\begin{array}{l}9.69 \\
9.48\end{array}$ & $\begin{array}{l}5.69 \\
5.90 \\
5.97\end{array}$ & $\begin{array}{l}0.000\left(\pi \rightarrow \sigma^{*}\right) \\
0.000\left(\pi \rightarrow \sigma^{*}\right) \\
0.196\end{array}$ & 9.35 & $\begin{array}{l}6.11\left(\pi \rightarrow \sigma^{*}\right) \\
6.25\end{array}$ & 9.38 [44] & 5.90 [45] \\
\hline $\begin{array}{c}\text { 1H-benzimidazole } \\
\mathrm{C}_{7} \mathrm{H}_{6} \mathrm{~N}_{2} \\
\text { (Isomer 1) }\end{array}$ & 8.84 & 4.63 & 0.245 & 8.40 & 4.67 & $8.44[42]$ & 4.47 [46] \\
\hline $\begin{array}{c}1 \mathrm{H} \text {-indazole } \\
\mathrm{C}_{7} \mathrm{H}_{6} \mathrm{~N}_{2} \\
\text { (Isomer 2) }\end{array}$ & 8.41 & 3.85 & 0.217 & 8.26 & 4.50 & 8.35 [47] & 4.27 [48] \\
\hline $\begin{array}{c}2 \mathrm{H} \text {-indazole } \\
\mathrm{C}_{7} \mathrm{H}_{6} \mathrm{~N}_{2} \\
\text { (Isomer } 2 \text { taut.) }\end{array}$ & 8.42 & 3.84 & 0.229 & 7.90 & 4.54 & & \\
\hline $\begin{array}{c}\text { 1H-pyrrolo[2,3-b] } \\
\text { pyridine } \\
\mathrm{C}_{7} \mathrm{H}_{6} \mathrm{~N}_{2} \\
\text { (Isomer 3) }\end{array}$ & 8.47 & 3.82 & 0.184 & 8.17 & 4.50 & 8.11 [49] & 4.28 [50] \\
\hline
\end{tabular}



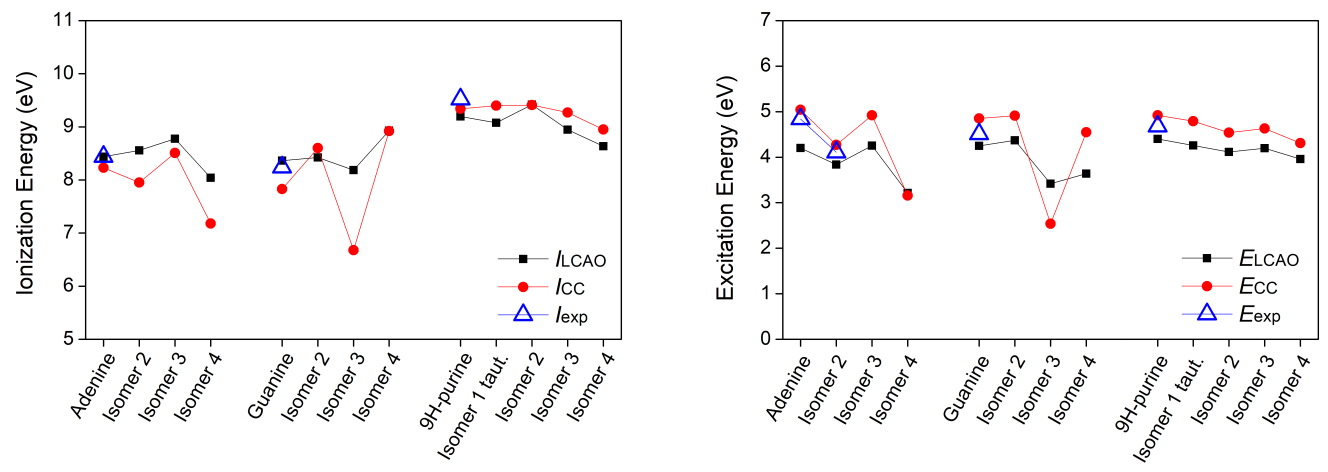

Figure 3. First $\pi$ ionization energy and first $\pi-\pi^{*}$ excitation energy of purines calculated via our LCAO method using all valence orbitals, along with results at the IP-EOMCCSD/aug-cc-pVDZ (vertical ionization energies) and CR-EOMCCSD(T)/aug-cc-pVDZ (vertical excitation energies) level of theory [29], as well as available experimental data. Different isomers are specified in Table 1.
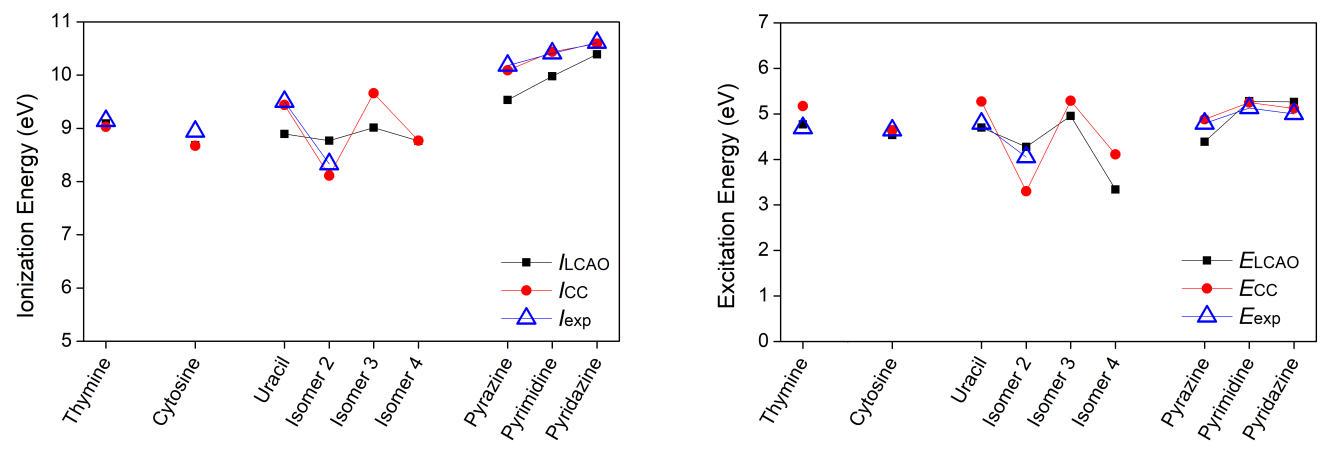

Figure 4. First $\pi$ ionization energy and first $\pi-\pi^{*}$ excitation energy of pyrimidines calculated via our LCAO method using all valence orbitals, along with results at the IP-EOMCCSD/aug-cc-pVDZ (vertical ionization energies) and CR-EOMCCSD(T)/aug-cc-pVDZ (vertical excitation energies) level of theory [29], as well as available experimental data.
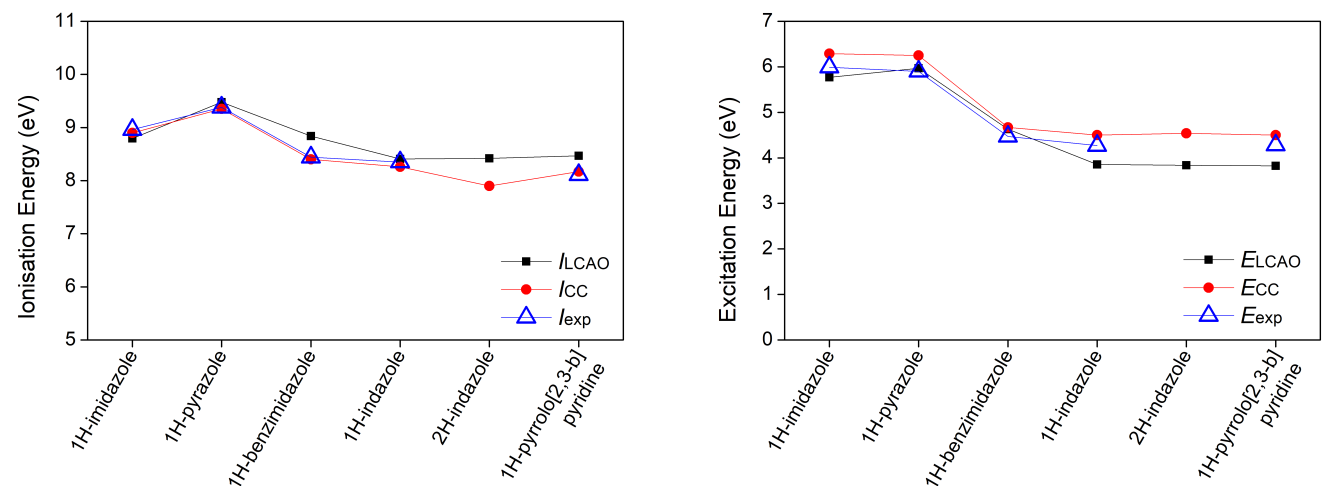

Figure 5. First $\pi$ ionization energy and first $\pi-\pi^{*}$ excitation energy of other planar heterocyclic molecules calculated via our LCAO method using all valence orbitals, along with results calculated at the IP-EOMCCSD/aug-cc-pVDZ (vertical ionization energies) and CR-EOMCCSD(T)/aug-cc-pVDZ (vertical excitation energies) level of theory [29], as well as available experimental data. 
Regarding the ionization energy, the LCAO obtained results are in very good agreement with both the experimental data and the $\mathrm{CC}$ results, although there are some deviations. The Root Mean Square Percentage Error (RMSPE), with respect to the experimental values, is $3.65 \%$. Differences in tautomer ionization energies are as expected negligible, that is $0.12 \mathrm{eV}$ for purine tautomers and $0.01 \mathrm{eV}$ for indazole tautomers. As for the excitation energies of the $\pi-\pi^{*}$ transition, the RMSPE, with respect to the experimental values, is $6.49 \%$. Both purine and indazole tautomers have a negligible $0.03 \mathrm{eV}$ difference in their excitation energies. Based on the presented data and reported comments about individual bases, we note that the LCAO method used in this work, though not exact, is capable of producing results in a good agreement with experimental data, when choosing the suitable set of parameters. This outcome has motivated the use of the same method for all other systems of interest, whose computational results are presented in the remainder of this article. Vertical ionization energies of nucleic acid bases in the gas phase with different electronic structure methods are, generally, in agreement with our results, cf. Reference [51] and references therein.

\subsection{B-DNA Base Pairs}

In this subsection, we present our results for the B-DNA base pairs. In Table 5, we show the HOMO, LUMO, and HOMO-LUMO gap energies of the two B-DNA base pairs (Adenine (A)-Thymine (T) and Guanine $(\mathrm{G})$-Cytosine $(\mathrm{C})$ ), according to the procedure described in Section 2.3 using LCAO with all valence orbitals, along with the corresponding energies found in Ref. [52] using only $2 p_{z}$ orbitals. At this point, we should state that the bases making up the base pairs are slightly deformed in comparison to their structure when isolated (cf. Section 3.1), so the corresponding HOMO and LUMO energies for these two cases may differ. Thus, Table 5 also contains the HOMO, LUMO, and HOMOLUMO gap energies of the distorted bases. The HOMO (LUMO) energies are of $\pi\left(\pi^{*}\right)$ molecular orbital character and the HOMO-LUMO gap energies are $\pi-\pi^{*}$ transitions, unless otherwise stated.

Table 5. HOMO $\left(E_{\mathrm{LCAO}, \mathrm{H}}\right)$ and LUMO $\left(E_{\mathrm{LCAO}, \mathrm{L}}\right)$ eigenenergies of the base pairs A-T and G-C, obtained in this work using LCAO with all valence orbitals, along with the corresponding HOMO-LUMO energy gaps ( $E_{\mathrm{LCAO}, \mathrm{g}}$ ) in $\mathrm{eV}$ (rows 6 and 7 ). Rows 2-5 contain the calculated HOMO and LUMO energies of each distorted base making up these base pairs. The third, fifth, and the seventh columns list the corresponding energies from Reference [52] where only $2 p_{z}$ orbitals had been used.

\begin{tabular}{|c|c|c|c|c|c|c|}
\hline Base or Base Pair & $E_{\mathrm{LCAO}, \mathrm{H}}$ & $E_{\mathrm{H}}[52]$ & $E_{\mathrm{LCAO}, \mathrm{L}}$ & $E_{\mathrm{L}}[52]$ & $E_{\mathrm{LCAO}, \mathrm{g}}$ & $E_{\mathrm{g}}[52]$ \\
\hline A & -8.50 & -8.30 & -4.19 & -4.40 & 4.31 & 3.90 \\
\hline $\mathrm{T}$ & -9.12 & -9.00 & -4.30 & -4.90 & 4.82 & 4.10 \\
\hline G & -8.31 & -8.00 & -4.12 & -4.50 & 4.19 & 3.50 \\
\hline C & -8.67 & -8.80 & $\begin{array}{l}-4.43\left(\sigma^{*}\right) \\
-4.11\end{array}$ & -4.30 & $\begin{array}{l}4.24\left(\pi \rightarrow \sigma^{*}\right) \\
4.56\end{array}$ & 4.50 \\
\hline A-T & -8.49 & -8.30 & -4.31 & -4.90 & 4.18 & 3.40 \\
\hline G-C & -8.30 & -8.00 & $\begin{array}{l}-4.43\left(\sigma^{*}\right) \\
-4.14\end{array}$ & -4.50 & $\begin{array}{l}3.87\left(\pi \rightarrow \sigma^{*}\right) \\
4.16\end{array}$ & 3.50 \\
\hline
\end{tabular}

The energy values for the bases are slightly different from those in Table 4, as expected. In addition, based on Table 5, one can assume that the HOMO energy of a particular base pair is very close to the largest of the HOMO energies of the two bases of the base pair, while the LUMO energy of the base pair is closer to the lowest of the two LUMO energies. 
In Figures 6 and 7 we represent the occupation probabilities of holes and electrons on each atomic orbital of bases and base pairs, calculating the squared coefficients $\left|c_{i v}\right|^{2}$ (cf. Equations (1) and (12)) of the corresponding states (HOMO for holes, LUMO for electrons). We observe that our calculated HOMO state for the base pair A-T (G-C) is localized almost totally in Adenine (Guanine), while the corresponding LUMO wave function is localized in Thymine (Cytosine), in accordance to results from ab initio techniques of References $[53,54]$, which locate the HOMO of a base pair in purine and the LUMO in pyrimidine. This is due to the higher HOMO energy of Adenine (Guanine) and lower LUMO energy of Thymine (Cytosine) and the large values of these differences compared to the transfer integrals (see Table 6). We calculate the first transition character of A, T, A-T, and $\mathrm{G}$ to be $\pi-\pi^{*}$, while $\mathrm{C}$ and G-C have $\pi-\sigma^{*}$ transition character.
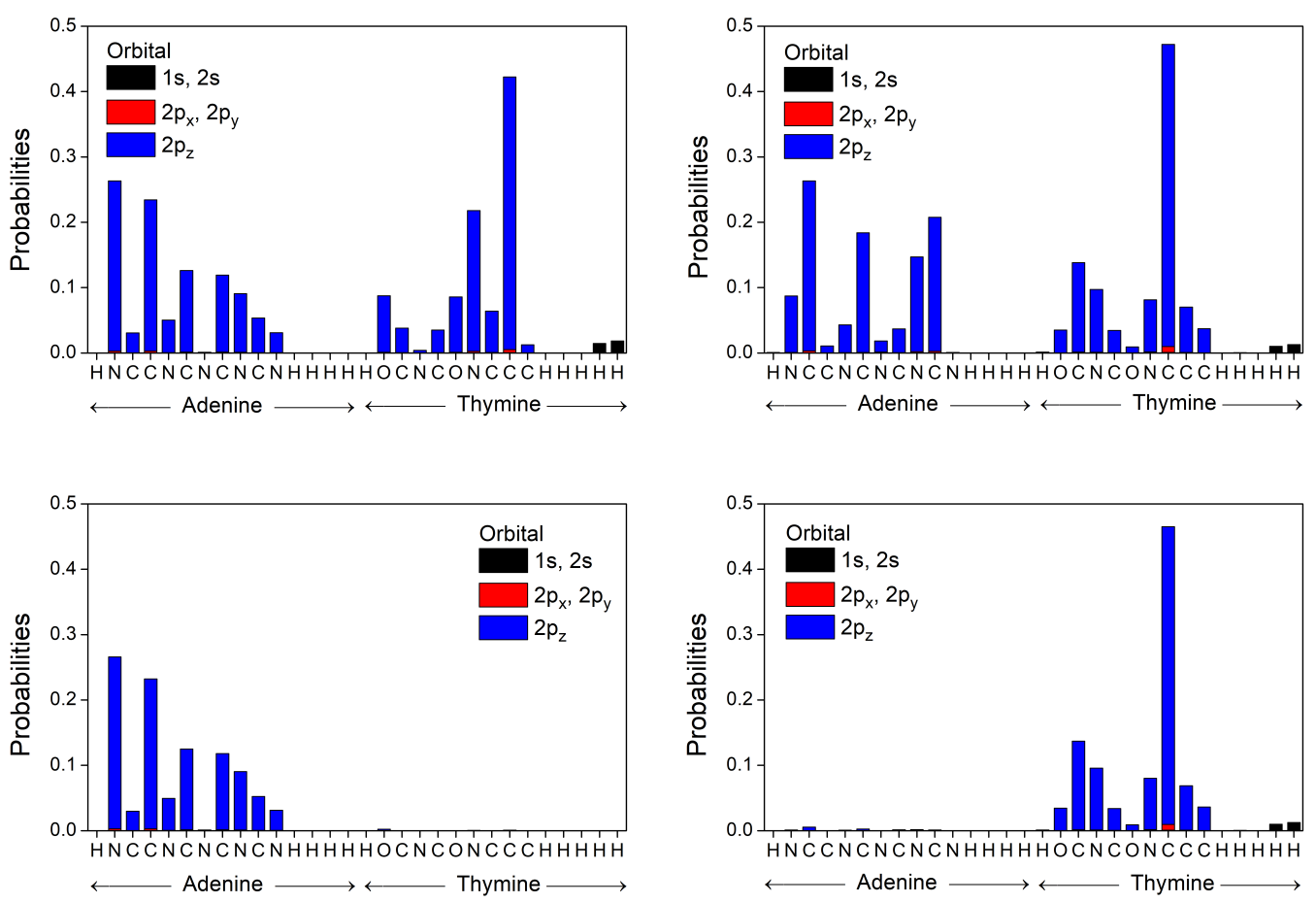

Figure 6. Occupation probabilities of each atomic orbital, $\left|c_{i v}\right|^{2}$ (cf. Equation (1)), for the HOMO (left) and LUMO (right) states of A and T bases into an A-T base pair (top), along with the corresponding probabilities (cf. Equation (12)) for the HOMO and LUMO states of the A-T base pair (bottom).

We obtain the charge transfer parameters between two successive base pairs by calculating the corresponding overlap integrals from Equation (26). We denote by XY two successive base pairs, $X-X_{\text {compl }}$ and $Y-Y_{\text {compl }}$. The bases $X$ and $Y$ are located at the same strand in the direction $5^{\prime}-3^{\prime}$, while $X_{\text {compl }}$ and $Y_{\text {compl }}$, respectively, are their complementary bases on the other strand. In the most common B-DNA conformation, $X-X_{\text {compl }}$ and Y-Y $\mathrm{Y}_{\text {compl }}$ are approximately separated by $3.4 \AA$ and twisted by $36^{\circ}$.

Table 6 summarizes our LCAO results using all valence orbitals for the transfer parameters, for all possible combinations of successive base pairs and close-to-ideal geometrical conformations. The Table also contains comparisons with other methods. 

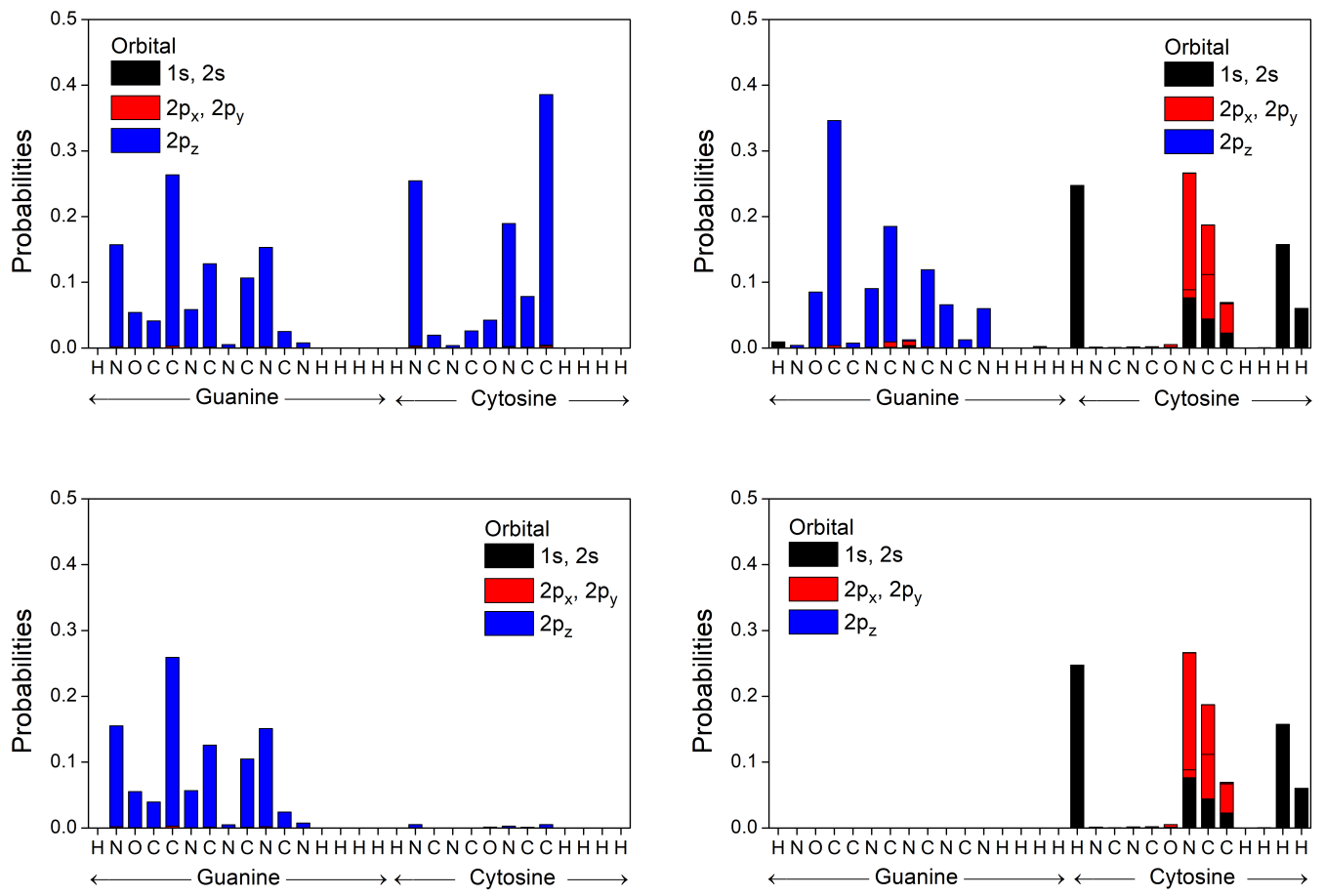

Figure 7. Occupation probabilities of each atomic orbital, $\left|c_{i v}\right|^{2}$ (cf. Equation (1)), for the HOMO (left) and LUMO (right) states of G and C bases into a G-C base pair (top), along with the corresponding probabilities (cf. Equation (12)) for the HOMO and LUMO states of the G-C base pair (bottom).

Table 6. Close-to-ideal geometrical conformations. The absolute values of transfer parameters for all possible combinations of successive base pairs. $\left|t_{\mathrm{LCAO}, \mathrm{H}}\right|\left(\left|t_{\mathrm{LCAO}, \mathrm{L}}\right|\right)$ of the second (fifth) column refer to hole (electron) transfer parameters obtained from our LCAO calculations using all valence orbitals. The third column lists hole transfer parameters of Reference [55], an estimation from various articles found in bibliography. The sixth column lists the electron transfer parameters of Reference [52], where only $2 \mathrm{p}_{z}$ orbitals had been used. The fourth and seventh columns list the transfer parameters with the parameterization of Reference [29], where only $2 \mathrm{p}_{z}$ orbitals had been used. All transfer parameters are given in $\mathrm{meV}$.

\begin{tabular}{|c|c|c|c|c|c|c|}
\hline$X Y$ & $\left|t_{\mathrm{LCAO}, \mathrm{H}}\right|$ & $\left|t_{\mathrm{H}}\right|[55]$ & $\left|t_{\mathrm{H}}\right|$ [29] & $\left|t_{\mathrm{LCAO}, \mathrm{L}}\right|$ & $\left|t_{L}\right|[52]$ & $\left|t_{L}\right|[29]$ \\
\hline GG, CC & 116 & 100 & 51 & $\begin{array}{l}92\left(\sigma^{*}\right) \\
2\end{array}$ & 20 & 8 \\
\hline AG, CT & 37 & 30 & 32 & $\begin{array}{l}11\left(\sigma^{*}\right) \\
11\end{array}$ & 3 & 10 \\
\hline TG, CA & 28 & 10 & 4 & $\begin{array}{l}2\left(\sigma^{*}\right) \\
9\end{array}$ & 17 & 10 \\
\hline AC, GT & 16 & 10 & 3 & $\begin{array}{l}1\left(\sigma^{*}\right) \\
1\end{array}$ & 32 & 23 \\
\hline TC, GA & 142 & 110 & 57 & $\begin{array}{l}3\left(\sigma^{*}\right) \\
6\end{array}$ & 1 & 7 \\
\hline AA, TT & 38 & 20 & 32 & 22 & 29 & 17 \\
\hline AT & 50 & 35 & 6 & 1 & 1 & 1 \\
\hline TA & 37 & 50 & 10 & 2 & 2 & 1 \\
\hline GC & 10 & 10 & 10 & $\begin{array}{l}2\left(\sigma^{*}\right) \\
19\end{array}$ & 10 & 19 \\
\hline CG & 75 & 50 & 13 & $\begin{array}{l}1\left(\sigma^{*}\right) \\
9\end{array}$ & 8 & 13 \\
\hline
\end{tabular}


In Figure 8, we illustrate the absolute values of transfer parameters for all possible combinations of successive base pairs for holes and for electrons. The figure contains the transfer parameters obtained from our LCAO calculations using all valence orbitals, along with the corresponding parameters found in Ref. [55] (where various estimations from bibliography had been taken into account). Furthermore, those from Ref. [29], where only $2 p_{z}$ orbitals had been used, and finally, electron transfer parameters from Ref. [52], where only $2 \mathrm{p}_{z}$ orbitals had been used. Peluso et al. [56], based on electrochemical and time-dependent spectroscopic measurements, find for GG a transfer integral $\approx 0.1 \mathrm{eV}$, which is very close to our results, while, for $\mathrm{AA}$, they report a value $\approx 0.3 \mathrm{eV}$, which seems large compared to the parametrization reported here taking into account all valence orbitals as well as to the parametrization in Reference [55], which takes into account, for holes, the works [52,57-61].
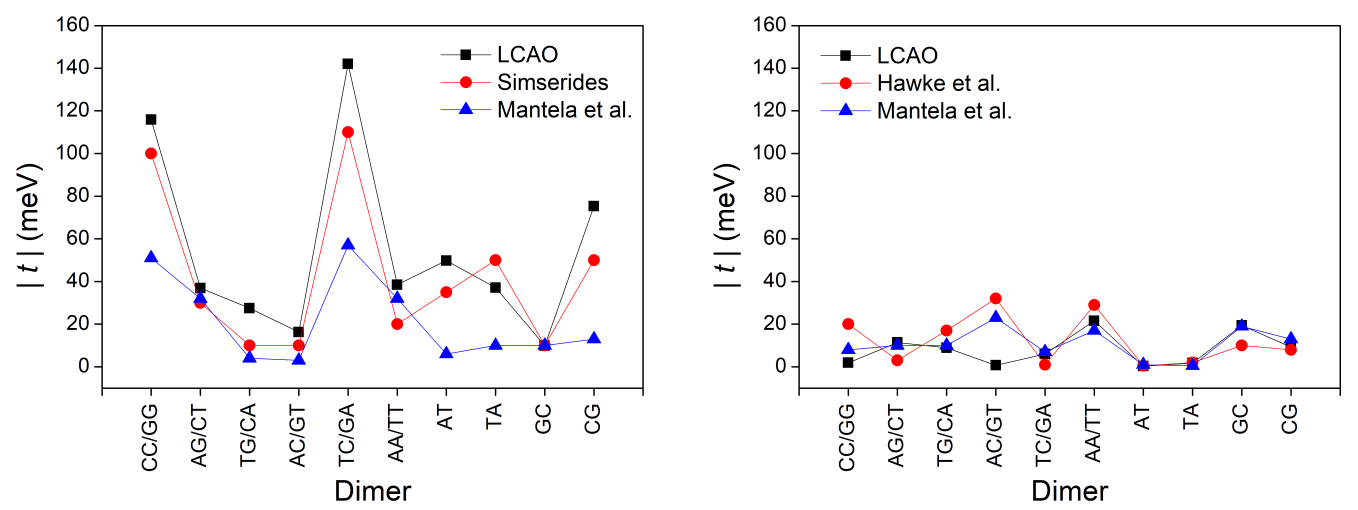

Figure 8. The absolute values of transfer parameters for all possible combinations of successive base pairs for holes (left) and for electrons (right). We show the transfer parameters obtained from our LCAO calculations using all valence orbitals, as well as the corresponding transfer parameters found in Reference [55] (for holes, estimation from various articles in bibliography), in Reference [29] (using only $2 \mathrm{p}_{z}$ orbitals) and in Reference [52] (for electrons, using only $2 \mathrm{p}_{z}$ orbitals).

In Figure 9, we depict the maximum transfer percentage of Equation (28) obtained by our LCAO calculations using all valence orbitals, compared to the values using parameters from Reference [55] for holes (an estimation from various articles from bibliography). Furthermore, from Reference [29] for electrons and holes as well as from Reference [52] for electrons (where only $2 \mathrm{p}_{z}$ orbitals had been used). For ideal B-DNA geometries and for dimers made of identical monomers, the maximum transfer percentage is 1 , while in the case of different monomers, $p$ is smaller than 1 , both for holes and for electrons. Both for $t$ and $p$, we observe that the current LCAO using all valence orbitals is closer to the results from Reference [55] for holes (where various estimations from bibliography of different origin had been taken into account). For electrons, as far as we know this current LCAO calculation is the only one beyond simple Hückel models, using only $2 \mathrm{p}_{z}$ orbitals. 

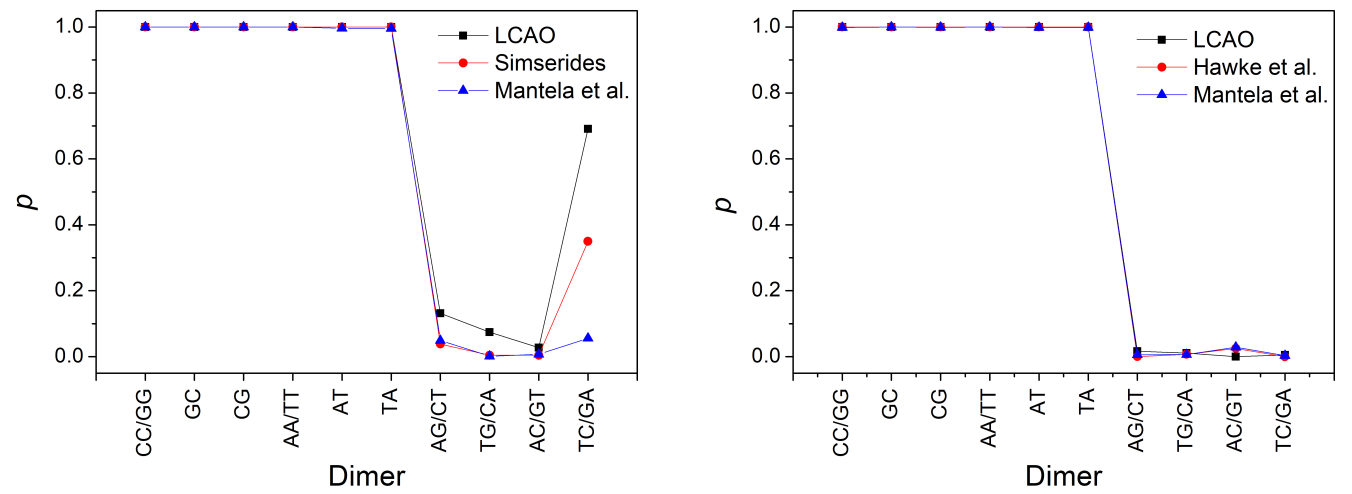

Figure 9. Comparison of the maximum transfer percentage $p$ obtained by our LCAO method using all valence orbitals, with the $p$ values extracted from other sources: obtained from parameters found in Reference [55] (for holes, estimation from various articles in bibliography), in Reference [29] (using only $2 p_{z}$ orbitals) and in Reference [52] (for electrons, using only $2 p_{z}$ orbitals). Left panel for holes, right panel for electrons.

\subsection{Effects of Structural Variability}

In this subsection, we analyze the effects of structural variability on the electronic structure and charge transfer properties of B-DNA using the fragments derived from MD, as detailed in Section 2.4. In Figure 10, we present the absolute values of the parameters $\Delta$ (difference between the HOMO eigenenergies of the two base pairs of each studied dimer) and $t$ (transfer integral between the two base pairs' HOMOs of each studied dimer), as well as the maximum transfer percentages $p$ as calculated via Equation (28). The values of $|t|$ and $p$ can also be found in Reference [16] in comparison with results obtained by Density Functional Theory (DFT) techniques.

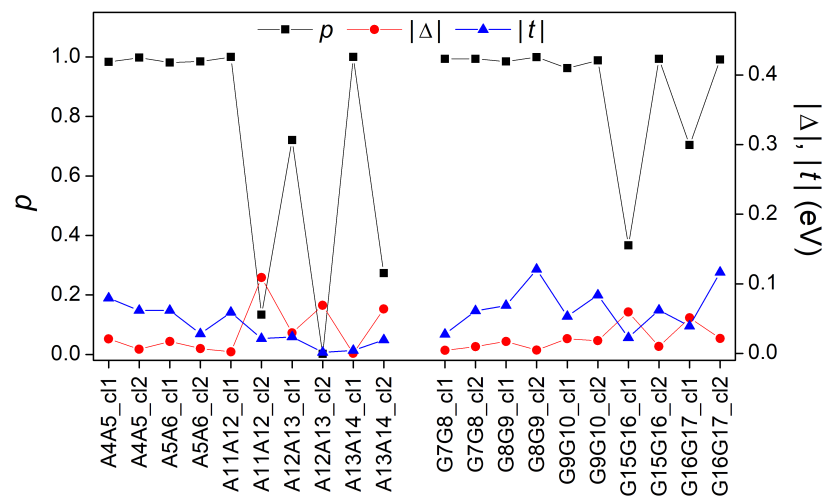

Figure 10. The parameters $|\Delta|$ and $|t|$, as well as the maximum transfer percentage $p$ for all the dimers of the MD oligomer.

From Equation (28) it is expected that ideal dimers (made up of ideal monomers) should have a maximum transfer percentage equal to 1 . However, by observing Figure 10, one can notice that not all AA and GG dimers have $p=1$. Specifically, dimers with a $p$ considerably different from unit (and a $\Delta$ different than zero) are: A11A12_cl2, A12A13_cl1, A121A13_cl2, A13A14_cl2, G15G16_cl1, and G16G17_cl1. This is expected because the studied monomers are not ideal, which means their consisting bases have relative translations and rotations (Figure 1) as depicted in Figure 2. More specifically, a small $p$ value is related to a large $\Delta$ value, in accordance with Equation (28). Thus, it is expected that the structural parameters (shear, stretch, stagger, buckle, propeller twist, opening) have a reasonable effect on the HOMO (and LUMO) base-pair energy values and consequently on the values of $\Delta$ and $p$. As for the contribution of transfer integrals $t$ to the above discussion, it is documented in Reference [16]. 


\section{Conclusions and Outlook}

In this work, we computed the tight-binding parameters that are necessary for a wiremodel description of longitudinal (axial) charge transfer through B-DNA. We took into account structural variability by carrying out these computations for multiple structures resulting from a classical trajectory.

We initially calculated the lowest ionization and excitation energies of various "ideal" (frozen) heterocyclic organic molecules with a biological function, including the DNA and RNA bases and isomers. We did so employing the LCAO approximation in a new parameterization that accounts for all valence orbitals, i.e., $2 \mathrm{~s}, 2 \mathrm{p}_{x}, 2 \mathrm{p}_{y}, 2 \mathrm{p}_{z}$ orbitals for $\mathrm{C}$, $\mathrm{N}$ and $\mathrm{O}$ atoms and $1 \mathrm{~s}$ orbital for $\mathrm{H}$ atoms. This LCAO approach is more suitable than the standard LCAO parameterization to investigate non-planar geometries. We predict ionization and excitation energies with RMSPE 3.65\% and 6.49\%, respectively, compared to the experimental values. Based on these errors, we infer that the proposed computational strategy is an adequate tool for a quick and relatively accurate estimation of the electronic structure for a variety of organic molecules.

Using the computed energies of the HOMO and LUMO within the proposed LCAO method, we then evaluated the energy levels of DNA base pairs (A-T, G-C) and the transfer integrals between stacked base pairs. Our results are in good agreement with reference data. The obtained transfer integrals can be used in further studies of charge transfer/transport in DNA oligomers and polymers.

Finally, we addressed the impact of structural flexibility (dynamics) on the electronic structure and charge transfer ability of B-DNA. To this end, we applied our LCAO method to $20 \mathrm{AA}$ and GG dimers, extracted from representative structures in a classical MD trajectory of a $20 \mathrm{mer}$ evolved for $500 \mathrm{~ns}$. For all these systems, we calculated the parameters $\Delta$ and $t$, as well as the maximum transfer percentage between the two monomers of a dimer $p$. We found that the values of $\Delta$ and $p$ are significantly affected by geometrical changes. Nevertheless, in the vast majority of the studied dimers, the maximum transfer percentage is very close to unity.

We suggest that the proposed methodology can be used in a high-throughput manner to characterize dynamical effects on charge transfer in organic polymers constituted of heterocyclic building blocks.

Our cost-effective simple method is suitable for very fast computations of electronic structure and transfer integrals. It can greatly facilitate charge transfer and transport calculations in sequences of arbitrary geometry taken, e.g., by MD simulations, as far as purines, pyrimidines, and similar molecules are the constituents. Although we took only valence orbitals for carbon, nitrogen, oxygen, and hydrogen into account, this approach can be generalized to include other atomic species and orbitals.

Author Contributions: Conceptualization, C.S. and R.D.F.; methodology, M.M. and C.S. and R.D.F.; software, M.M., C.S. and R.D.F.; validation, C.S. and R.D.F.; formal analysis, M.M.; investigation, M.M.; resources, M.M. and C.S. and R.D.F.; data curation, M.M.; writing-original draft preparation, M.M.; writing—review and editing, M.M. and C.S. and R.D.F.; visualization, M.M.; supervision, C.S. and R.D.F.; project administration, C.S. and R.D.F.; funding acquisition, M.M. and C.S. and R.D.F. All authors have read and agreed to the published version of the manuscript.

Funding: M.M. wishes to thank the State Scholarships Foundation (IKY). This research is co-financed by Greece and the European Union (European Social Fund-ESF) through the operational programme "Human Resources Development, Education and Lifelong Learning" in the context of the project "Strengthening Human Resources Research Potential via Doctorate Research" (MIS-5000432), implemented by the State Scholarships Foundation (IKY). R.D.F. acknowledges the Center for Advanced Research Computing (CARC) for computing resources, the Zumberge fund, and the Women in Science and Engineering program at the University of Southern California. The APC is expected to be funded partially by C.S. referee vouchers and partially by the National and Kapodistrian University of Athens open access program.

Data Availability Statement: Data available upon reasonable request. 
Acknowledgments: We thank K. Lambropoulos and A. Morphis for useful discussions.

Conflicts of Interest: The authors declare no conflict of interest.

Abbreviations
$\begin{array}{ll}\text { The following abbreviations are used in this manuscript: } \\ \text { LCAO } & \text { Linear Combination of Atomic Orbitals } \\ \text { MD } & \text { Molecular Dynamics } \\ \text { DNA } & \text { Deoxyribonucleic Acid } \\ \text { TB } & \text { Tight Binding } \\ \text { IP-EOMCCSD } & \text { Ionization Potential Equation of Motion } \\ & \text { Coupled Cluster with Singles and Doubles } \\ \text { CR-EOMCCSD(T) } & \text { Completely Renormalized Equation Of Motion } \\ & \text { Coupled Cluster with Singles, Doubles, and non-Iterative Triples } \\ \text { RMSPE } & \text { Root Mean Square Percentage Error } \\ \text { HOMO } & \text { Highest Occupied Molecular Orbital } \\ \text { LUMO } & \text { Lowest Unoccupied Molecular Orbital }\end{array}$

\section{References}

1. Kawai, K.; Majima, T. Hole Transfer Kinetics of DNA. Acc. Chem. Res. 2013, 46, 2616-2625. [CrossRef]

2. Dandliker, P.J.; Holmlin, R.E.; Barton, J.K. Oxidative Thymine Dimer Repair in the DNA Helix. Science 1997, $275,1465-1468$. [CrossRef]

3. Rajski, S.R.; Jackson, B.A.; Barton, J.K. DNA repair: Models for damage and mismatch recognition. Mutat. Res. 2000, 447, 49-72. [CrossRef]

4. Giese, B. Electron transfer through DNA and peptides. Bioorgan. Med. Chem. 2006, 14, 6139-6143. [CrossRef] [PubMed]

5. Shih, C.T.; Cheng, Y.Y.; Wells, S.A.; Hsu, C.L.; Römer, R.A. Charge transport in cancer-related genes and early carcinogenesis. Comput. Phys. Commun. 2011, 182, 36-38. [CrossRef]

6. Páez, C.J.; Schulz, P.A.; Wilson, N.R.; Römer, R.A. Robust signatures in the current-voltage characteristics of DNA molecules oriented between two graphene nanoribbon electrodes. New J. Phys. 2012, 14, 093049. [CrossRef]

7. Shih, C.T.; Roche, S.; Römer, R.A. Point-Mutation Effects on Charge-Transport Properties of the Tumor-Suppressor Gene p53. Phys. Rev. Lett. 2008, 100, 018105. [CrossRef]

8. Oliveira, J.I.N.; Albuquerque, E.L.; Fulco, U.L.; Mauriz, P.W.; Sarmento, R.G.; Caetano, E.W.S.; Freire, V.N. Conductance of single microRNAs chains related to the autism spectrum disorder. Europhys. Lett. 2014, 107, 68006. [CrossRef]

9. Wohlgamuth, C.H.; McWilliams, M.A.; Slinker, J.D. DNA as a Molecular Wire: Distance and Sequence Dependence. Anal. Chem. 2013, 85, 8634-8640. [CrossRef]

10. Lewis, F.D.; Wasielewski, M.R. Dynamics and efficiency of photoinduced charge transport in DNA: Toward the elusive molecular wire. Pure Appl. Chem. 2013, 85, 1379-1387. [CrossRef]

11. Seeman, N.C. DNA in a material world. Nat. Nanotechnol. 2003, 421, 427-431. [CrossRef]

12. Shapir, E.; Cohen, H.; Calzolari, A.; Cavazzoni, C.; Ryndik, D.; Cuniberti, G.; Kotlyar, A.; Di Felice, R.; Porath, D. Electronic structure of single DNA molecules resolved by transverse scanning tunnelling spectroscopy. Nat. Mater. 2008, 7, 68-74. [CrossRef] [PubMed]

13. Genereux, J.C.; Barton, J.K. Mechanisms for DNA Charge Transport. Chem. Rev. 2010, 110, 1642-1662. [CrossRef] [PubMed]

14. Livshits, G.; Stern, A.; Rotem, D.; Borovok, N.; Eidelshtein, G.; Migliore, A.; Penzo, E.; Wind, S.; Di Felice, R.; Skourtis, S.; et al. Long-range charge transport in single G-quadruplex DNA molecules. Nat. Nanotechnol. 2014, 9, 1040-1046. NNANO.2014.246. [CrossRef]

15. Wang, K. DNA-Based Single-Molecule Electronics: From Concept to Function. J. Funct. Biomater. 2018, 9, 8. [CrossRef]

16. Mantela, M.; Morphis, A.; Lambropoulos, K.; Simserides, C.; Di Felice, R. Effects of Structural Dynamics on Charge Carrier Transfer in B-DNA: A Combined MD and RT-TDDFT Study. J. Phys. Chem. B 2021, 125, 3986-4003. [CrossRef] [PubMed]

17. Slater, J.C.; Koster, G.F. Simplified LCAO Method for the Periodic Potential Problem. Phys. Rev. 1954, 94, 1498-1524. [CrossRef]

18. Harrison, W.A. Electronic Structure and the Properties of Solids: The Physics of the Chemical Bond, 2nd ed.; Dover: New York, NY, USA, 1989.

19. Harrison, W.A. Elementary Electronic Structure; World Scientific: River Edge, NJ, USA, 1999.

20. Menon, M.; Allen, R.E. Simulations of atomic processes at semiconductor surfaces: General method and chemisorption on GaAs(110). Phys. Rev. B 1988, 38, 6196-6205. [CrossRef] [PubMed]

21. Menon, M.; Subbaswamy, K.R. Nonorthogonal tight-binding molecular-dynamics study of silicon clusters. Phys. Rev. B 1993, 47, 12754-12759. [CrossRef] [PubMed]

22. Menon, M.; Connolly, J.; Lathiotakis, N.; Andriotis, A. Tight-binding molecular-dynamics study of transition-metal clusters. Phys. Rev. B 1994, 50, 8903-8906. [CrossRef] 
23. Lambropoulos, K.; Simserides, C. Periodic, quasiperiodic, fractal, Kolakoski, and random binary polymers: Energy structure and carrier transport. Phys. Rev. E 2019, 99, 032415. [CrossRef] [PubMed]

24. Dickerson, R. Definitions and nomenclature of nucleic acid structure components. Nucleic Acids Res. 1989, 17, 1797-1803. [CrossRef]

25. Olson, W.K.; Bansal, M.; Burley, S.K.; Dickerson, R.E.; Gerstein, M.; Harvey, S.C.; Heinemann, U.; Lu, X.J.; Neidle, S.; Shakked, Z.; et al. A Standard Reference Frame for the Description of Nucleic Acid Base-pair Geometry. J. Mol. Biol. 2001, 313, 229-237. [CrossRef] [PubMed]

26. Lavery, R.; Moakher, M.; Maddocks, J.H.; Petkeviciute, D.; Zakrzewska, K. Conformational analysis of nucleic acids revisited: Curves+. Nucleic Acids Res. 2009, 37, 5917-5929. [CrossRef]

27. Mazur, J.; Jernigan, R.L. Comparison of Rotation Models for Describing DNA Conformations: Application to Static and Polymorphic Forms. Biophys. J. 1995, 68, 1472-1489. [CrossRef]

28. Ussery, D. DNA Structure: A-, B- and Z-DNA Helix Families. Encycl. Life Sci. 2002, 1-7. [CrossRef]

29. Mantela, M.; Morphis, A.; Tassi, M.; Simserides, C. Lowest ionisation and excitation energies of biologically important heterocyclic planar molecules. Mol. Phys. 2016, 114, 709-718. [CrossRef]

30. Hilborn, R.C. Einstein coefficients, cross sections, f values, dipole moments, and all that. Am. J. Phys. 1982, 50, 982-986. [CrossRef]

31. Hush, N.; Cheung, A.S. Ionization potentials and donor properties of nucleic acid bases and related compounds. Chem. Phys. Lett. 1975, 34, 11-13. [CrossRef]

32. Clark, L.B.; Peschel, G.G.; Tinoco, I. Vapor Spectra and Heats of Vaporization of Some Purine and Pyrimidine Bases. J. Phys. Chem. 1965, 69, 3615-3618. [CrossRef]

33. Voet, D.; Gratzer, W.B.; Cox, R.A.; Doty, P. Absorption spectra of nucleotides, polynucleotides, and nucleic acids in the far ultraviolet. Biopolymers 1963, 1, 193-208. [CrossRef]

34. Santhosh, C.; Mishra, P. Electronic spectra of 2-aminopurine and 2,6-diaminopurine: phototautomerism and fluorescence reabsorption. Spectrochim. Acta Part A Mol. Spectrosc. 1991, 47, 1685-1693. [CrossRef]

35. Clark, L.B.; Tinoco, I. Correlations in the Ultraviolet Spectra of the Purine and Pyrimidine Bases1. J. Am. Chem. Soc. 1965, 87, 11-15. [CrossRef]

36. Maier, J.P.; Muller, J.F.; Kubota, T. Ionisation Energies and the Electronic Structures of the N-oxides of diazabenzenes. Helv. Chim. Acta 1975, 58, 1634-1640. [CrossRef]

37. Kubota, T. Electronic Spectra and Electronic Structures of Some Basic Heterocyclic N-Oxides. Bull. Chem. Soc. Jpn. 1962, 35, 946-955. [CrossRef]

38. Gleiter, R.; Heilbronner, E.; Hornung, V. Photoelectron Spectra of Azabenzenes and Azanaphthalenes: I. Pyridine, diazines, s-triazine and s-tetrazine. Helv. Chim. Acta 1972, 55, 255-274. [CrossRef]

39. Pisanias, M.N.; Christophorou, L.G.; Carter, J.G.; McCorkle, D.L. Compound-negative-ion resonance states and threshold-electron excitation spectra of N-heterocyclic molecules: Pyridine, pyridazine, pyrimidine, pyrazine, and sym-triazine. J. Chem. Phys. 1973, 58, 2110-2124. [CrossRef]

40. Bolovinos, A.; Tsekeris, P.; Philis, J.; Pantos, E.; Andritsopoulos, G. Absolute vacuum ultraviolet absorption spectra of some gaseous azabenzenes. J. Mol. Spectrosc. 1984, 103, 240-256. [CrossRef]

41. Halverson, F.; Hirt, R.C. Near Ultraviolet Solution Spectra of the Diazines. J. Chem. Phys. 1951, 19, 711-718. [CrossRef]

42. Ramsey, B.G. Substituent effects on imidazole basicity and photoelectron spectroscopy determined ionization energies. J. Org. Chem. 1979, 44, 2093-2097. [CrossRef]

43. Caswell, D.S.; Spiro, T.G. Ultraviolet resonance Raman spectroscopy of imidazole, histidine, and Cu(imidazole)42+: Implications for protein studies. J. Am. Chem. Soc. 1986, 108, 6470-6477. [CrossRef]

44. Lichtenberger, D.L.; Copenhaver, A.S. Ionization band profile analysis in valence photoelectron spectroscopy. J. Electron Spectrosc. Relat. Phenom. 1990, 50, 335-352. [CrossRef]

45. Noyce, D.S.; Ryder, E.; Walker, B.H. The ultraviolet absorption spectra of substituted pyrazoles. J. Org. Chem. 1955, 20, 1681-1686. [CrossRef]

46. Gordon, R.D.; Yang, R.F. Vapor absorption spectra of benzoxazole, benzimidazole, and benzothiazole near $2850 \AA$ A. Can. J. Chem. 1970, 48, 1722-1729. [CrossRef]

47. Kovać, B.; Klasinc, L.; Stanovnik, B.; Tišler, M. Photoelectron spectroscopy of heterocycles. Azaindenes and azaindolizines. J. Heterocycl. Chem. 1980, 17, 689-694. [CrossRef]

48. Cané, E.; Trombetti, A.; Velino, B.; Caminati, W. Assignment of the 290-nm electronic band system of indazole [1,2-benzodiazole] as $\pi^{*}-\pi$ by rotational band contour analysis. J. Mol. Spectrosc. 1992, 155, 307-314. [CrossRef]

49. Fuke, K.; Yoshiuchi, H.; Kaya, K.; Achiba, Y.; Sato, K.; Kimura, K. Multiphoton ionization photoelectron spectroscopy and two-color multiphoton ionization threshold spectroscopy on the hydrogen bonded phenol and 7-azaindole in a supersonic jet. Chem. Phys. Lett. 1984, 108, 179-184. [CrossRef]

50. Ilich, P. 7-Azaindole: The low-temperature near-UV/vis spectra and electronic structure. J. Mol. Struct. 1995, 354, 37-47. [CrossRef]

51. Pluhařová, E.; Slavíček, P.; Jungwirth, P. Modeling Photoionization of Aqueous DNA and Its Components. Acc. Chem. Res. 2015, 48, 1209-1217. [CrossRef] 
52. Hawke, L.G.D.; Kalosakas, G.; Simserides, C. Electronic parameters for charge transfer along DNA. Eur. Phys. J. E 2010, 32, 291-305. [CrossRef] [PubMed]

53. Varsano, D.; Di Felice, R.; Marques, M.; Rubio, A. A TDDFT Study of the Excited States of DNA Bases and Their Assemblies. J. Phys. Chem. B 2006, 110, 7129-7138. [CrossRef]

54. Mallajosyula, S.S.; Datta, A.; Pati, S.K. Structure and electronic properties of the Watson-Crick base pairs: Role of hydrogen bonding. Synth. Met. 2005, 155, 398-401. [CrossRef]

55. Simserides, C. A systematic study of electron or hole transfer along DNA dimers, trimers and polymers. Chem. Phys. 2014, 440, 31-41. [CrossRef]

56. Peluso, A.; Caruso, T.; Landi, A.; Capobianco, A. The Dynamics of Hole Transfer in DNA. Molecules 2019, 24, 4044. [CrossRef]

57. Endres, R.G.; Cox, D.; Singh, R.R.P. Colloquium: The quest for high-conductance DNA. Rev. Mod. Phys. 2004, 76, 195-214. [CrossRef]

58. Voityuk, A.A.; Jortner, J.; Bixon, M.; Rösch, N. Electronic coupling between Watson-Crick pairs for hole transfer and transport in desoxyribonucleic acid. J. Chem. Phys. 2001, 114, 5614-5620. [CrossRef]

59. Migliore, A.; Corni, S.; Varsano, D.; Klein, M.L.; Di Felice, R. First Principles Effective Electronic Couplings for Hole Transfer in Natural and Size-Expanded DNA. J. Phys. Chem. B 2009, 113, 9402-9415. [CrossRef]

60. Kubař, T.; Woiczikowski, P.B.; Cuniberti, G.; Elstner, M. Efficient Calculation of Charge-Transfer Matrix Elements for Hole Transfer in DNA. J. Phys. Chem. B 2008, 112, 7937-7947. [CrossRef]

61. Ivanova, A.; Shushkov, P.; Rösch, N. Systematic Study of the Influence of Base-Step Parameters on the Electronic Coupling between Base-Pair Dimers: Comparison of A-DNA and B-DNA Forms. J. Phys. Chem. A 2008, 112, 7106-7114. [CrossRef] [PubMed] 